\title{
Gendered exposures: Exploring the role of paid and unpaid work through life in U.S. women's cardiovascular health
}

\author{
Emily Q. Ahonen ${ }^{*}$, K. Fujishiro ${ }^{b}$, S. Brown ${ }^{\mathrm{c}}$, Y. Wang ${ }^{\mathrm{d}}$, A.J. Palumbo ${ }^{\mathrm{e}}$, and Y.L. Michael ${ }^{\mathrm{f}}$
}

"Department of Social and Behavioral Sciences, Indiana University-Purdue University Indianapolis, Indianapolis, United States of America; ${ }^{b}$ Division of Field Studies and Engineering, National Institute for Occupational Safety and Health, Cincinnati, United States of America; 'Department of Biostatistics, Indiana University School of Medicine, Indianapolis, Indiana, United States of America; ${ }^{d}$ Department of Environmental Health Science, Indiana University, Indianapolis, Indiana, United States of America; ${ }^{\mathrm{e}}$ Department of Epidemiology and Biostatistics, Temple University, Philadelphia, United States of America; ${ }^{\mathrm{f}}$ Department of Epidemiology and Biostatistics, Drexel University, Philadelphia, United States of America

*Department of Social and Behavioral Sciences, Richard M. Fairbanks School of Public Health, 1050 Wishard Blvd (RG 6094), Indianapolis, Indiana 46219 USA; eqahonen@iu.edu

The paper explores how paid and unpaid labor history over the life course influence women's cardiovascular disease. U.S. women comprise about $50 \%$ of the paid workforce and perform the majority of unpaid labor. However, the influence of women's work on their health is under-researched. Our sample was drawn from the Women's Health Initiative Observational Study, a cohort of post-menopausal women in the U.S. aged 50-79 at recruitment. Women were categorized into five groups according to paid labor history: worked in paid jobs consistently throughout adult life; left the workforce early; entered the workforce later; discontinuous work history; never worked outside the home. Live birth history (none, at least one, missing) served as a proxy for unpaid labor in prime age. Cox proportional hazard models were used to estimate the hazard ratio of CVD associated with different paid work histories. We then assessed the effect of unpaid labor on the relation between paid labor and CVD. Paid labor participation was not associated with CVD risk among women without unpaid labor after adjusting for age, education, and birth cohort.

Among those with unpaid demands, leaving the workforce early or having discontinuous work history was protective. In this U.S. sample, the association between paid work participation history and CVD risk depends on the presence of unpaid labor. Our results demonstrate the necessity of including work - paid and unpaid - in consideration of women's health.

This is the author's manuscript of the article published in final edited form as:

Ahonen, E. Q., Fujishiro, K., Brown, S., Wang, Y., Palumbo, A. J., \& Michael, Y. L. (2020). Gendered exposures: Exploring the role of paid and unpaid work throughout life in U.S. women's cardiovascular health. Critical Public Health, 1-11. https://doi.org/10.1080/09581596.2020.1854183 
Keywords: unpaid labor; occupational health; cardiovascular disease; Women's Health Initiative

\section{Introduction}

Existing research on occupational health has generally assumed that women share men's experiences at work. It concludes, for example, that paid labor influences health directly (e.g., through occupational injury) and indirectly (e.g. through sleep disturbance), and that unemployment is consistently associated with poorer health. Worklessness, or the lack of work which is built into the structure and function of labor markets, also patterns population health (Bambra 2011). The relative quality of both employment and working conditions also influence health in ways that may be deleterious or beneficial to health. However, evidence suggests women's experiences of work differ from men's (Armstrong and Messing 2014). Long-accepted ideas in occupational health research, such as the healthy worker bias, appear to function differently in women than they do in men. A recent study found that while both men and women who were not in the workforce had poorer health than those who were employed (i.e., the healthy worker effect), that association was weaker in women, and it was greatly attenuated when the number of children in the household was considered (Johnson et al. 2017). That is, some women are likely out of the workforce because of family care demands, not because of poor health. Study of occupational exposure specific to women has been limited (Messing 1997; Messing and Mager Stellman 2006). Much occupational health research is built on either an abstract, nonembodied worker (Ferree and Hall 1996) or the "ideal worker" who is a male and has the "backstage support of a stay-at-home wife" (Williams, Blair-Loy, and Berdahl 2013, 210), making women anomalies, and therefore complicators of study design. 
Despite significant increases in women's participation in the paid workforce over the last few decades (Toossi, Morisi, and U.S. Bureau of Labor Statistics 2017), their burden of unpaid labor (e.g., household tasks, caregiving, and the socializing of others outside of a paid marketplace) has not significantly lessened (Artazcoz, Borrell, and Benach 2001; C. E. Bird 1999; MacDonald, Phipps, and Lethbridge 2005; Rosenfield 1989; Jung and O’Brien 2019). Women in the United States perform more unpaid labor than men (Krantz-Kent, 2009). To date, limited research has evaluated the role of unpaid labor while considering the relation between paid labor and health.

We propose that public discourse in the U.S. about women and paid labor has put aside the realities and value of unpaid labor. To the degree that this discourse has occurred, it has been insufficient in relevant institutions to prompt changes in policy that accommodate and recognize the societal need for both paid and unpaid labor (Schmidt 2010). Most U.S. women have limited structural support for multiple responsibilities, such as affordable childcare, eldercare, or paid family leave, thus increasing the difficulty of managing multiple demands. We furthermore suggest that U.S.-wide and regional labor markets, workplaces, and families as institutions have not shifted in parallel with women's participation in paid labor because of structural sexism.

Structural sexism creates health inequity as institutions function to distribute power and resources based on gender at the macro (policy - e.g. persistent wage gaps), meso (family and workplace dynamics and procedures), and micro (socialization, internalization) levels (Homan 2019). Work — both paid and unpaid — distributes power and resources throughout life stages and consequently creates accumulations of advantages and disadvantages over time (Cockerham, Hamby, and Oates 2017; Mortimer and Shanahan 2007). Structural sexism might leave women with insufficient power, autonomy, or resources to use in support of their health as they move 
through life. Researchers have long understood sexism as a form of stratification enacted primarily at the interpersonal and intrapersonal levels, and therefore conducted limited analyses of stratification at the meso and macro levels of institutions (Ferree and Hall 1996). However, these levels play a significant role in determining the health impacts of sexism (Homan 2019). We examine work using the perspective of structural sexism because work is both part of, and shaped by, meso- and macro-level institutions. Paid and unpaid labor are lenses on the bargaining power of women in the employer-employee relationship and within their family units. Here we propose two major connections linking labor and the health of women: time and roles.

Lack of time might limit other healthful activities women could undertake, such as exercise (Winkler et al. 2020), healthful food preparation (Dixon et al. 2014), and sleep (Winkler et al. 2020). Longer hours in paid labor have been associated with increased CVD risk (Kivimäki et al. 2015). Working long hours was recently tied to significantly increased risk for several chronic diseases in a large study, and was problematic for women compared to men (Dembe and Yao 2016). This study did not consider time spent on unpaid labor as exposure. The combined load of paid and unpaid responsibilities may also be stressful, leading to poorer health behaviors (Rosenfield 1989; Dembe and Yao 2016; Virtanen et al. 2011; Sabbath et al. 2015; Bird and Rieker 2008). Furthermore, women and those who experience work-family conflict are more likely than men to report the need to rush (Strazdins et al. 2016). Stress also causes fatigue, which limits options for using down time (Strazdins et al. 2016). Thus, women may spend more time working than men and experience greater stress.

Role theory focuses on socially-defined categories into which people fit and the behaviors specific to the context (expectations, norms, etc.) of each category. Roles such as "wife," "mother," "daughter" and "employee" may carry conflicting expectations. Studies using 
role theory have generally found that work-family conflict affects women in ways distinct from men (Artazcoz, Borrell, and Benach 2001; MacDonald, Phipps, and Lethbridge 2005; Griep et al. 2016). People might manage competing demands in the meso domains of work and family by using increasingly available flexible paid work arrangements, although, for women this challenges roles in both domains. Working for pay undermines role expectations related to family nurturance, and using flexible arrangements makes it impossible to fulfil the role of the ideal worker who is completely dedicated to her paid job (Williams, Blair-Loy, and Berdahl 2013). The flexibility stigma (Williams, Blair-Loy, and Berdahl 2013) often leads workers to compensate by working more intensely or longer, perpetuating the scarcity and intensity of time.

We hypothesize that paid work as well as work which is not paid influences peoples' health. By conceptualizing work to encompass paid and unpaid labor, we are able to interrogate paid employment and family as institutions that are social determinants of health and health disparities in themselves, and which tie to other social determinants of health (Ahonen et al. 2018). We engage discursive institutionalism (Schmidt 2010), institutions at multiple levels of experience (Homan 2019; Ferree and Hall 1996), and role and time theories about how labor's influence on health may persist into late life in a structurally sexist milieu (Homan 2019). We hope to contribute to a discourse which is fuller in its examination of work, and therefore one that can more accurately assess the health effects of labor within the working reality of American women.

In this study we focus on cardiovascular disease (CVD) as an important health consequence of paid and unpaid labor. CVD causes significant disease burden and is the most common cause of death in women in the U.S. (Coulter 2011; Mensah and Brown 2007; Mosca et al. 2000). An association between paid labor and CVD is robust in men (Schnall et al. 2000), but 
questions remain about it in women (Klumb and Lampert 2004). This paper addresses a significant research gap by exploring the impact of unpaid labor on the relation between paid labor during working age and CVD later in life.

\section{Materials and methods}

Data sources and sample: We used data from the Women's Health Initiative Observational Study (WHI OS), a prospective cohort study of post-menopausal women aged 50-79 at recruitment, which took place between 1993 and 1998 at 40 clinical centers in the U.S. The eligibility criteria, in addition to sex and age, included postmenopausal status, the willingness to stay in the geographic area of enrollment for at least three years, and an ability and willingness to consent to participation (Hays et al. 2003). Langer and colleagues provide further details (Langer et al. 2003). In this study, we used information collected at a baseline enrollment session, including a physical examination, in-person interview, and self-administered questionnaire (Controlled Clinical Trials 1998). We focused on the history of paid labor participation and childbearing (see below for details of measures). Of the 93,676 women who completed a baseline interview, we excluded those with a history of CVD $(\mathrm{N}=17,528)$, those for whom we could not construct a paid work history $(\mathrm{N}=3,127)$, those who did not have a recorded follow-up time $(\mathrm{N}=302)$, and those who had missing information on variables related to our study questions. This resulted in an analytic sample of 68,615 women. CVD incidence data were available up to February 2017; the median follow-up duration was 17.9 years in our analytic sample.

\section{Measures}

Paid work history: At baseline, WHI OS participants were asked if they "ever had a paid job." 
Women responding yes provided information on up to three longest-held paid jobs, starting with the most recent, including their current job if they were in the workforce. Based on the beginning and ending years of each job, participants' paid labor history was constructed and categorized according to the following patterns: worked in paid jobs consistently throughout adult life; left the workforce early; entered the workforce later; discontinuous work history; never worked outside the home (Palumbo et al. 2019).

Unpaid work in prime age: The number of reported live births served as a proxy for unpaid labor in prime working age under the assumption that raising a child followed each birth. The reported number of live births was categorized into none, at least one, and information missing. CVD event: The WHI OS made follow-up contact with participants annually through phone calls, in-person interviews, or self-completed forms. Participants self-reported CVD in the form of diagnosis of coronary heart disease, ischemic or hemorrhagic stroke. If the participant died, hospital records, autopsy reports, and/or death certificates were reviewed to determine cause of death. A local physician adjudicator verified all self-reported events through a review of medical records and death certificates. Central cardiovascular adjudicators then reviewed the locally verified events. Periodically during the OS, staff also reviewed the National Death Index to ascertain the cause of death and to investigate loss to follow up (Curb et al. 2003). Demographic information: Education was reported at the baseline. Age was self-reported. We constructed birth cohorts (1910-19, 20-29, 30-39, and 40-49) in order to capture the cohort effect on paid labor participation, education, and any associated unmeasured influence on heart health (e.g., public health campaign against smoking).

Statistical analyses: We first tabulated the demographic characteristics of the final sample. To investigate the differences in CVD risk among women with different paid 
employment and live-birth histories, we calculated age-adjusted rates of CVD incidence per 1000 person-years by paid work history and by live-birth history. Next, to assess the influence of unpaid labor on the relationship between paid labor and CVD, we stratified the sample by live-birth history and used the Cox proportional hazard model to estimate the hazard ratio (HR) of CVD associated with paid work history. Models were adjusted for age and birth cohort only, then education was added. All analyses were completed using SAS $^{\mathrm{TM}}$ (SAS Institute Inc. (version SAS ${ }^{\circledR}$ 9.4 Statements: Reference.) 2013).

\section{Results}

Table 1 displays demographic and social characteristics of our study sample. The most common type of paid work participation pattern was consistently throughout adult life (40.0\%), followed by entering the workforce late (27.8\%), and having discontinuous work history (23.9\%). Few left the workforce early in life (7.5\%). Discontinuous and early leaving correlated with being slightly older. Majorities in all categories except consistent work had some college or vocational studies. Most women who worked consistently attained more than a college degree. Most women reported one or more live births. Ten percent did not report their birth history, and this group disproportionately consisted of women who worked consistently. Because they were a significant portion of the sample, we kept them in the analysis by assigning a code for missing.

\section{$=====$ INSERT TABLE 1 ABOUT HERE $====$}

Table 2 shows age-adjusted CVD rates per 1000 person-years by paid and unpaid labor history. Those who worked consistently and entered the workforce later in life were at 
lower risk of CVD than those in other categories; however, the $95 \%$ confidence interval (CIs) for all groups overlapped. As for unpaid labor, the rate of CVD was higher for those with our proxy of at least one birth than for those who reported no births, but again the 95\% CIs overlapped.

\section{$=====$ INSERT TABLE 2 ABOUT HERE $====$}

Table 3 shows the HRs associated with paid labor history stratified by birth history, adjusted for age, education, and birth cohort. Among those with no live birth, paid labor participation history was not associated with CVD risk. However, among those with one or more live births, women who left the workforce early or had discontinuous work history had lower risk for CVD than those who worked consistently throughout life. These associations were not affected by controlling for birth cohort or education. Among those who did not report birth information, discontinuous work history was associated with higher risks of CVD compared with working consistently throughout life. By contrast discontinuous work history was protective for women with unpaid labor history.

\section{$=====$ INSERT TABLE 3 ABOUT HERE $====$}

Sensitivity analyses: Because women in the WHI cohort were asked about only up to three jobs they had held, starting with the most recent, those who had more than three jobs may have been misclassified. Specifically, those women who were classified as "entered the workforce late" might have had more jobs than they reported, and thus may be closer to the worked consistently or discontinuously group. But results were in unchanged if we combined entered later in life with discontinuous work history or entered later in life with worked continuously (see supplementary online materials). 
Additional post hoc analyses: We used women who had worked consistently throughout their adult lives as our reference category, but that choice could obscure important differences by birth history among the women in that category. Therefore, we re-assessed our analyses in just that group, and found no significant difference in CVD risk (Appendix Table A1).

To better understand the women who did not report birth history, we compared them to those who did report (Appendix Table A2). We noticed that over a third of the women with missing birth information were never married. Given the substantial differences in marital history in the sample, we re-analyzed data with the assumption that missing birth information from women who never married meant no birth. The results were not changed from our main analysis (supplementary online materials).

\section{Discussion}

We envisioned work as the combination of paid and unpaid labor. We also proposed that gendered role expectations for women within institutions and time might link work to women's health over the life course. Our data showed that the association between paid work participation history and CVD risk depends on unpaid labor history. That is, among the women who reported live births (a proxy for unpaid labor), leaving the paid workforce early or having discontinuous paid work history was protective. In descriptive analyses, neither paid work participation history nor unpaid work history (approximated by live birth history) on its own appeared to have an association with CVD risk. Overall, these results suggest that managing paid labor demands was protective when unpaid demands existed. Additionally, discontinuous paid work history in women who reported no live birth was a marker of poor health.

Role theory suggests that women with fewer conflicts among multiple roles or demands 
for time will be healthier, and women in our sample who had unpaid labor and also had less consistent paid labor histories were protected from CVD. This finding is also consistent with a recent research finding that the threshold of weekly work hours that are detrimental to health is lower for women than for men. The authors concluded that setting women's paid work hours lower than men's would avoid gender-based health inequities resulting from the added burden of women shouldering more unpaid labor than men (Dinh, Strazdins, and Welsh 2017). In this data set we were unable to directly explore the number of hours worked either in paid or unpaid labor, having only the cumulative number of years worked in paid labor and women's report of live births as a proxy indicator for time spent in unpaid labor. Future studies should directly assess time spent on both paid and unpaid labor in nuanced ways (Strazdins et al. 2016) along with health to understand the experience of long work hours directly (Dembe and Yao 2016; Kivimäki et al. 2015).

Health impact could result from long hours creating limited time for health supportive activities (Winkler et al. 2020), the stress created by rushing (Strazdins et al. 2016), or poorer health behaviors (Virtanen et al. 2011; Dembe and Yao 2016; Sabbath, Mejía-Guevara, et al. 2015; Rosenfield 1989; C. Bird and Rieker 2008). As well, labor might lead to CVD later in life because of damage done in younger ages or through health-damaging habits which are formed early and persist. This begs the question of who is able to leave the paid workforce, or to come and go - that is, who might be able to obtain protection from the burden of too many roles or time demands. On one hand, women who are poor enough to qualify for support (e.g., lowincome health insurance schemes, welfare, food assistance) could potentially leave the paid workforce. The structure of many such programs in the U.S. make that unlikely, but this may be relevant elsewhere. At the other end of the spectrum, women who are financially well-off or 
who have support from others (e.g., a high-earning spouse or wealthy extended family), may be able to leave paid employment. Sabbath and colleagues (Sabbath, Guevara, et al. 2015) found that adjustment for late-life household wealth attenuated mortality risk for women with multiple role configurations. Williams and colleagues (2013) have also delineated the ways in which class shapes the stigma of workers who manage multiple life demands through paid work flexibility. The demands of paid and unpaid labor may exacerbate income- and class-based health inequities in women if some women do not have alternatives to manage those demands. We were not able to incorporate income throughout the women's life-course in this analysis, but future studies should do so. This will require more detailed data on family structure and support systems, both within the family unit and from employers and broader society.

Our findings, if replicated, have important implications for occupational health research and practice, particularly because no policy mechanism addresses health problems related to work which is not "work" as defined by a market-based location. The discourse surrounding policies related to labor markets, workplaces, and families depends on framing paid labor using a model that assumes an unencumbered male breadwinner (Dinh, Strazdins, and Welsh 2017; Strazdins et al. 2016). This results in superficial social and institutional support for women's participation in paid labor combined with economic realities that often require it for individual women and for families. For instance, access to paid sick leave is limited in the U.S., and those who have sick time often must use it to care for others - like an ill child. The lack of structural social policies to support unpaid labor in the U.S., continued greater performance of unpaid labor by women, and phenomena like the flexibility stigma reflect limited shifts in institutional practices (Williams, Blair-Loy, and Berdahl 2013). Ongoing separation of "real" work and unpaid work has implications for population health. Researchers infrequently interrogate 
gender-based patterns of labor for the ways in which they create differential access to resources, autonomy, self-determination, and power (Ferree and Hall 1996) in broader society, in workplaces, and in families. Unless the prevailing discourse challenges institutional practices related to work (Schmidt 2010), women's - and men's (Homan 2019) - health will likely continue to suffer.

Challenges to the current discourse require an evolved conception of work. For instance, micro-economics researchers consider the value of household labor to a society, and feminist thinking has critiqued the distribution of this labor and how that relates to its social value (Jung and O’Brien 2019). Our results suggest that a similar move toward more complex thinking about work and health could enrich occupational health research. Doing so, however, would require better measurement of labor, both paid and unpaid. Society derives enormous benefit from both types of labor, and yet even the occupational health research about women's recognized (paid) work has not been conducted with adequate scientific or conceptual rigor. For example, our study, like that of Johnson and colleagues (2017), suggests accepted occupational health wisdom about the healthy worker bias may not apply to women. In our study, when we examined paid and unpaid labor together, working for pay was less consistently health protective for women with a history of unpaid labor. That is, just because labor does not take place in the market (is not "productive" labor) doesn't mean it doesn't affect the lives of people doing it - including their health.

Public health researchers must more fully consider work in their analyses (Ahonen et al. 2018), and occupational health researchers should incorporate more nuanced thinking about labor and its effects on health in populations. Opportunities for population health improvement arise when we adequately measure the influence of an issue on the well-being of people. With 
adequate evidence, society can make changes to labor, social, and economic practice that would better support the health of people who perform both paid and unpaid labor (Jung and O'Brien 2019; Robertson 1999).

\section{Limitations}

The work history patterns of the women in our sample may not represent the broader population of U.S. women. However, previous analyses using the same employment history categorization (Palumbo et al. 2019) found that the patterns in women in the WHI sample were very similar to the occupational patterns of women in other U.S. and international samples. While it covers a large segment of adult life, our measure of paid labor history does not identify specific types of jobs or time arrangements. Additionally, this study did not directly assess unpaid labor. Instead, we used live birth history, a crude indicator of unpaid labor, and do not have information about child-raising or levels of partner/family support. Furthermore, we were not able to account for other forms of unpaid labor, such as housework and elder care (Jung and O'Brien 2019) or the contributions of others in the household towards the household work. While child-rearing is a major portion of time spent in unpaid labor for U.S. women (KrantzKent 2009), unpaid labor takes many forms beyond care for one's own children that merit future exploration.

Moreover, the relationship between paid and unpaid labor and health can be mutually determining. For instance, having had no live births could be a marker of poor health in those women who reported it. Likewise, never having worked for pay outside the home could be a marker of poor health, or, conversely, of financial privilege and stability which would be protective of health in this group of women. We cannot fully account for all possibilities because our data preclude more detailed explorations. Finally, in our post-hoc analyses, we 
assumed that women who did not report birth history and who were never married had no children. This is likely a more nuanced issue, and merits further exploration of how not reporting birth history may or may not relate to employment history or health in future studies.

The sample was predominantly white, which prevented us from addressing any differences which might exist by race/ethnicity. However, these results in women, among whom a majority possess racial privilege, suggest that investigations that include unpaid labor will be important for racial/ethnic groups who may also be at racial or ethnically-based social disadvantage (Williams, Blair-Loy, and Berdahl 2013).

\section{Conclusions}

This study suggests that women's unpaid work influences their health through its interrelationship with paid work, making it vital that population health research consider both forms of labor. Multiple perspectives, from public health and beyond, should be used to further explore these combined influences. The volume of paid and unpaid labor performed by women has broad implications for their health; future research should match its potential import with rigor and nuance.

\section{Acknowledgements}

The WHI program is funded by the National Heart, Lung, and Blood Institute, National Institutes of Health, U.S. Department of Health and Human Services through contracts HHSN268201600018C, HHSN268201600001C, HHSN268201600002C, HHSN268201600003C, and HHSN268201600004C.

\section{Declaration of Interest}

The authors have no conflicts of interest to declare.

The findings and conclusions in this report are those of the authors and do not necessarily reflect 
the official position of the National Institute for Occupational Safety and Health, Centers for

Disease Control and Prevention.

\section{References}

Ahonen, E. Q., K Fujishiro, T Cunningham, and M Flynn. 2018. "Work as an Inclusive Part of Population Health Inequities Research and Prevention." American Journal of Public Health.

Armstrong, Pat, and Karen Messing. 2014. "Taking Gender into Account in Occupational Health Research: Continuing Tensions." Policy and Practice in Health and Safety 12 (1): 3-16. doi:10.1080/14774003.2014.11667794.

Artazcoz, L, C Borrell, and J Benach. 2001. "Gender Inequalities in Health among Workers: The Relation with Family Demands." Journal of Epidemiology and Community Health 55 (9): 639-647. doi:10.1136/jech.55.9.639.

Bambra, Clare. 2011. Work, Worklessness, and the Political Economy of Health. Oxford: Oxford University Press.

Bird, CE, and Patricia P. Rieker. 2008. Gender and Health: The Effects of Constrained Choices and Social Policies. Cambridge University Press.

Bird, Chloe E. 1999. "Gender, Household Labor, and Psychological Distress: The Impact of the Amount and Division of Housework." Journal of Health and Social Behavior 40 (1): 32. doi: $10.2307 / 2676377$.

Cockerham, William C., Bryant W. Hamby, and Gabriela R. Oates. 2017. "The Social Determinants of Chronic Disease." American Journal of Preventive Medicine 52 (1S1): S5-S12. doi:10.1016/j.amepre.2016.09.010.

Controlled Clinical Trials. 1998. "Design of the Women's Health Initiative Clinical Trial and Observational Study. The Women's Health Initiative Study Group” 19 (1): 61-109. doi:10.1016/s0197-2456(97)00078-0.

Coulter, Stephanie A. 2011. "Epidemiology of Cardiovascular Disease in Women: Risk, Advances, and Alarms." Texas Heart Institute Journal 38 (2): 145-147.

Curb, J. David, Anne McTiernan, Susan R. Heckbert, Charles Kooperberg, Janet Stanford, Michael Nevitt, Karen C. Johnson, et al. 2003. "Outcomes Ascertainment and Adjudication Methods in the Women's Health Initiative." Annals of Epidemiology 13 (9 Suppl): S122-128. doi:10.1016/s1047-2797(03)00048-6.

Dembe, Allard E., and Xiaoxi Yao. 2016. "Chronic Disease Risks From Exposure to Long-Hour Work Schedules Over a 32-Year Period.” Journal of Occupational and Environmental Medicine / American College of Occupational and Environmental Medicine, June. doi:10.1097/JOM.0000000000000810.

Dinh, Huong, Lyndall Strazdins, and Jennifer Welsh. 2017. "Hour-Glass Ceilings: Work-Hour Thresholds, Gendered Health Inequities." Social Science \& Medicine 176 (March): 4251. doi:10.1016/j.socscimed.2017.01.024.

Dixon, J., D. Woodman, L. Strazdins, C. Banwell, D. Broom, and J. Burgess. 2014. "Flexible Employment, Flexible Eating and Health Risks." Critical Public Health 24 (4): 461-475. doi:10.1080/09581596.2013.852162. 
Ferree, Myra Marx, and Elaine J. Hall. 1996. "Rethinking Stratification from a Feminist Perspective: Gender, Race, and Class in Mainstream Textbooks." American Sociological Review; Washington 61 (6). Washington, United States, Washington: American Sociological Association: 929-950.

Griep, Rosane Härter, Susanna Toivanen, Cornelia van Diepen, Joanna M. N. Guimarães, Lidyane V. Camelo, Leidjaira Lopes Juvanhol, Estela M. Aquino, and Dóra Chor. 2016. "Work-Family Conflict and Self-Rated Health: The Role of Gender and Educational Level. Baseline Data from the Brazilian Longitudinal Study of Adult Health (ELSABrasil)." International Journal of Behavioral Medicine 23 (3): 372-382. doi:10.1007/s12529-015-9523-x.

Hays, Jennifer, Julie R. Hunt, F. Allan Hubbell, Garnet L. Anderson, Marian Limacher, Catherine Allen, and Jacques E. Rossouw. 2003. "The Women's Health Initiative Recruitment Methods and Results.” Annals of Epidemiology 13 (9 Suppl): S18-77. doi:10.1016/s1047-2797(03)00042-5.

Heidenreich, Paul A., Justin G. Trogdon, Olga A. Khavjou, Javed Butler, Kathleen Dracup, Michael D. Ezekowitz, Eric Andrew Finkelstein, et al. 2011. "Forecasting the Future of Cardiovascular Disease in the United States: A Policy Statement from the American Heart Association." Circulation 123 (8): 933-944. doi:10.1161/CIR.0b013e31820a55f5.

Homan, Patricia. 2019. "Structural Sexism and Health in the United States: A New Perspective on Health Inequality and the Gender System." American Sociological Review 84 (3). SAGE Publications Inc: 486-516. doi:10.1177/0003122419848723.

Johnson, Candice Y., Carissa M. Rocheleau, Christina C. Lawson, Barbara Grajewski, and Penelope P. Howards. 2017. "Factors Affecting Workforce Participation and Healthy Worker Biases in U.S. Women and Men.” Annals of Epidemiology 27 (9): 558-562.e2. doi:10.1016/j.annepidem.2017.08.017.

Jung, Ae-Kyung, and Karen M. O'Brien. 2019. "The Profound Influence of Unpaid Work on Women's Lives: An Overview and Future Directions." Journal of Career Development 46 (2): 184-200. doi:10.1177/0894845317734648.

Kivimäki, Mika, Markus Jokela, Solja T. Nyberg, Archana Singh-Manoux, Eleonor I. Fransson, Lars Alfredsson, Jakob B. Bjorner, et al. 2015. "Long Working Hours and Risk of Coronary Heart Disease and Stroke: A Systematic Review and Meta-Analysis of Published and Unpublished Data for 603,838 Individuals." Lancet (London, England) 386 (10005): 1739-1746. doi:10.1016/S0140-6736(15)60295-1.

Klumb, Petra L., and Thomas Lampert. 2004. "Women, Work, and Well-Being 1950-2000: A Review and Methodological Critique." Social Science \& Medicine (1982) 58 (6): 10071024. doi:10.1016/s0277-9536(03)00262-4.

Krantz-Kent, Rachel. 2009. "Measuring Time Spent in Unpaid Household Work: Results from the American Time Use Survey.” Monthly Labor Review, July, 14.

Krieger, N. 2001. "Theories for Social Epidemiology in the 21st Century: An Ecosocial Perspective.” International Journal of Epidemiology 30 (4): 668-677. doi:10.1093/ije/30.4.668.

Krieger, Nancy. 2010. "Workers Are People Too: Societal Aspects of Occupational Health Disparities — an Ecosocial Perspective." American Journal of Industrial Medicine 53 (2): 104-115. doi:10.1002/ajim.20759.

Langer, Robert D., Emily White, Cora E. Lewis, Jane M. Kotchen, Susan L. Hendrix, and Maurizio Trevisan. 2003. “The Women's Health Initiative Observational Study: Baseline 
Characteristics of Participants and Reliability of Baseline Measures." Annals of

Epidemiology 13 (9 Suppl): S107-121. doi:10.1016/s1047-2797(03)00047-4.

MacDonald, Martha, Shelley Phipps, and Lynn Lethbridge. 2005. "Taking Its Toll: The Influence of Paid and Unpaid Work on Women's Well-Being.” Feminist Economics 11 (1): 63-94. doi:10.1080/1354570042000332597.

Mensah, George A., and David W. Brown. 2007. "An Overview of Cardiovascular Disease Burden in the United States." Health Affairs (Project Hope) 26 (1): 38-48. doi: $10.1377 /$ hlthaff.26.1.38.

Messing, K. 1997. "Women's Occupational Health: A Critical Review and Discussion of Current Issues." Women \& Health 25 (4): 39-68. doi:10.1300/J013v25n04 03.

Messing, Karen, and Jeanne Mager Stellman. 2006. "Sex, Gender and Women's Occupational Health: The Importance of Considering Mechanism." Environmental Research 101 (2): 149-162. doi:10.1016/j.envres.2005.03.015.

Mortimer, Jeylan T., and Michael J. Shanahan. 2007. Handbook of the Life Course. Springer Science \& Business Media.

Mosca, L., W. K. Jones, K. B. King, P. Ouyang, R. F. Redberg, and M. N. Hill. 2000. "Awareness, Perception, and Knowledge of Heart Disease Risk and Prevention among Women in the United States. American Heart Association Women's Heart Disease and Stroke Campaign Task Force." Archives of Family Medicine 9 (6): 506-515.

Palumbo, Aimee J., Carolyn Cannuscio, Anneclaire J. De Roos, Lucy Robinson, Jana Mossey, Robert Wallace, Lorena Garcia, Aladdin H. Shadyab, Shawnita Sealy-Jefferson, and Yvonne Michael. 2019. "Women's Occupational Patterns and Later Life Physical Functioning." Journal of Aging and Health, January, 898264319826797. doi:10.1177/0898264319826797.

Puentes, Jennifer, and Matthew Gougherty. 2013. "Intersections of Gender, Race, and Class in Introductory Textbooks.” Teaching Sociology; Beverly Hills 41 (2). Beverly Hills, United States, Beverly Hills: American Sociological Association: 159-171. doi:http://dx.doi.org.proxy.ulib.uits.iu.edu/10.1177/0092055X12455527.

Rai, Shirin M., Catherine Hoskyns, and Dania Thomas. 2014. "Depletion: THE COST OF SOCIAL REPRODUCTION.” International Feminist Journal of Politics 16 (1): 86-105. doi:10.1080/14616742.2013.789641.

Robertson, Ann. 1999. "Health Promotion and the Common Good: Theoretical Considerations." Critical Public Health 9 (2): 117-133. doi:10.1080/09581599908402925.

Rosenfield, S. 1989. “The Effects of Women's Employment: Personal Control and Sex Differences in Mental Health." Journal of Health and Social Behavior 30 (1): 77-91.

Sabbath, Erika L., Ivan Mejía Guevara, M. Maria Glymour, and Lisa F. Berkman. 2015. "Use of Life Course Work-Family Profiles to Predict Mortality Risk Among US Women." American Journal of Public Health 105 (4): e96-e102. doi:10.2105/AJPH.2014.302471.

Sabbath, Erika L., Iván Mejía-Guevara, Clemens Noelke, and Lisa F. Berkman. 2015. "The Long-Term Mortality Impact of Combined Job Strain and Family Circumstances: A Life Course Analysis of Working American Mothers." Social Science \& Medicine (1982) 146 (December): 111-119. doi:10.1016/j.socscimed.2015.10.024.

SAS Institute Inc. (version SAS ${ }^{\circledR} 9.4$ Statements: Reference.). 2013. Cary, NC: SAS Institute Inc. 
Schmidt, Vivien A. 2010. "Reconciling Ideas and Institutions through Discursive Institutionalism.” In Ideas and Politics in Social Science Research, Ed.s Daniel Béland and Robert H. Cox, 76-95. Oxford, UNITED KINGDOM: Oxford University Press.

Schnall, P., K. Belkić, P. Landsbergis, and D. Baker. 2000. "Why the Workplace and Cardiovascular Disease?" Occupational Medicine (Philadelphia, Pa.) 15 (1): 1-6, iii.

Strazdins, Lyndall, Jennifer Welsh, Rosemary Korda, Dorothy Broom, and Francesco Paolucci. 2016. "Not All Hours Are Equal: Could Time Be a Social Determinant of Health?" Sociology of Health \& Illness 38 (1): 21-42. doi:10.1111/1467-9566.12300.

Toossi, Mitra, Teresa L Morisi, and U.S. Bureau of Labor Statistics. 2017. Women In The Workforce Before, During, And After The Great Recession.

U.S. Bureau of Labor Statistics. 2019. "Table A-1. Employment Status of the Civilian Population by Sex and Age." Economic News Release. https://www.bls.gov/news.release/empsit.t01.htm.

U.S. Bureau of Labor Statistics, and Hipple, Steven. 2016. "Labor Force Participation: What Has Happened since the Peak? : Monthly Labor Review: U.S. Bureau of Labor Statistics.” Monthly Labor Review. https://www.bls.gov/opub/mlr/2016/article/labor-forceparticipation-what-has-happened-since-the-peak.htm.

Virtanen, M., J. E. Ferrie, A. Singh-Manoux, M. J. Shipley, S. A. Stansfeld, M. G. Marmot, K. Ahola, J. Vahtera, and M. Kivimäki. 2011. "Long Working Hours and Symptoms of Anxiety and Depression: A 5-Year Follow-up of the Whitehall II Study." Psychological Medicine 41 (12): 2485-2494. doi:10.1017/S0033291711000171.

Williams, Joan C., Mary Blair-Loy, and Jennifer L. Berdahl. 2013. "Cultural Schemas, Social Class, and the Flexibility Stigma." Journal of Social Issues 69 (2). Wiley-Blackwell: 209-234. doi:10.1111/josi.12012.

Winkler, Megan R., Susan Telke, Emily Q. Ahonen, Melissa M. Crane, Susan M. Mason, and Dianne Neumark-Sztainer. 2020. "Constrained Choices: Combined Influences of Work, Social Circumstances, and Social Location on Time-Dependent Health Behaviors." SSM Population Health 11 (August): 100562. doi:10.1016/j.ssmph.2020.100562.

\section{Appendices}

Table A1. CVD cases, person-years, and age-adjusted CVD rates by unpaid labor characteristic among women who worked consistently throughout life.

\begin{tabular}{lllll}
\hline Unpaid Labor Characteristic & CVD cases & Person-years & CVD rate $^{\mathbf{1}}$ & (95\% CI) \\
\hline Reproductive history & & & & \\
No birth & 104 & 867.39 & 76.4 & $(0,170.5)$ \\
At least one birth & 1802 & 14319.43 & 84.6 & $(60.9,108.2)$ \\
Birth Information Missing & 367 & 2894.29 & 77.3 & $(27.0,127.7)$ \\
\hline
\end{tabular}

${ }^{1}$ Adjusted for age, $<55,55-59,60-64,65-69,50-74,>75$ 
Table A2. Demographic characteristics of women by reported birth history.

\begin{tabular}{|c|c|c|c|}
\hline \multirow{2}{*}{ Characteristic } & \multicolumn{3}{|c|}{ Birth history } \\
\hline & No births & At least one birth & Missing \\
\hline Total Number & 2210 & 59210 & 7195 \\
\hline Age, mean (SD) & $61.7(8.1)$ & $63.2(7.2)$ & $62.8(7.8)$ \\
\hline \multicolumn{4}{|l|}{ Birth Cohort, n (\%) } \\
\hline 1910-19 & $151(6.8)$ & $3744(6.3)$ & $574(8.0)$ \\
\hline $1920-29$ & $679(30.7)$ & $22374(37.8)$ & $2490(34.6)$ \\
\hline $1930-39$ & $826(37.4)$ & $25156(42.5)$ & $2825(39.3)$ \\
\hline $1940-49$ & $554(25.1)$ & $7936(13.4)$ & $1306(18.1)$ \\
\hline \multicolumn{4}{|l|}{ Education, n (\%) } \\
\hline Less than High School & $85(3.9)$ & $2717(4.6)$ & $165(2.3)$ \\
\hline High School or GED & $213(9.6)$ & $9951(16.8)$ & $760(10.6)$ \\
\hline Associates/Some College & $700(31.7)$ & $22100(37.3)$ & $1964(27.3)$ \\
\hline College Degree & $252(11.4)$ & $7075(12.0)$ & $867(12.0)$ \\
\hline More than College Degree & $960(43.4)$ & $17367(29.3)$ & $3439(47.8)$ \\
\hline \multicolumn{4}{|l|}{ Marital Status, n (\%) } \\
\hline Never Married & $377(17.1)$ & $300(0.5)$ & $2588(36.0)$ \\
\hline Divorced/Separated/widowed & $838(37.9)$ & $19322(32.6)$ & $1659(23.0)$ \\
\hline Married/in marriage-like relationship & $987(44.6)$ & $39458(66.7)$ & $2934(40.8)$ \\
\hline Missing & $8(0.4)$ & $130(0.2)$ & $14(0.2)$ \\
\hline
\end{tabular}




\section{SHORT LIST OF WHI INVESTIGATORS}

Program Office: (National Heart, Lung, and Blood Institute, Bethesda, Maryland) Jacques Rossouw, Shari Ludlam, Joan McGowan, Leslie Ford, and Nancy Geller

Clinical Coordinating Center: (Fred Hutchinson Cancer Research Center, Seattle, WA) Garnet Anderson, Ross Prentice, Andrea LaCroix, and Charles Kooperberg

Investigators and Academic Centers: (Brigham and Women's Hospital, Harvard Medical School, Boston, MA) JoAnn E. Manson;

(MedStar Health Research Institute/Howard University, Washington, DC) Barbara V. Howard; (Stanford Prevention Research Center, Stanford, CA)Marcia L. Stefanick; (The Ohio State University, Columbus, OH) Rebecca Jackson; (University of Arizona, Tucson/Phoenix, AZ) Cynthia A.Thomson; (University at Buffalo, Buffalo, NY) Jean Wactawski-Wende; (University of Florida, Gainesville/Jacksonville, FL) Marian Limacher; (University of Iowa, Iowa City/Davenport, IA) Jennifer Robinson; (University of Pittsburgh, Pittsburgh, PA) Lewis Kuller; (Wake Forest University School of Medicine, Winston-Salem, NC) Sally Shumaker; (University ofNevada, Reno, NV) Robert Brunner

Women's Health Initiative Memory Study: (Wake Forest University School of Medicine, Winston-Salem, NC) Mark Espelan 
Tables

Table 1. Demographic, social, and unpaid work history characteristics by paid work history of this study sample, drawn from the Women's Health Initiative Observational Study (WHI OS).

\begin{tabular}{|c|c|c|c|c|c|c|}
\hline \multirow[b]{2}{*}{ Characteristic } & \multicolumn{5}{|c|}{ Paid Work History } & \multirow[b]{2}{*}{$\begin{array}{c}\text { Total } \\
(\mathrm{n}=68615)\end{array}$} \\
\hline & $\begin{array}{c}\text { Worked } \\
\text { consistently } \\
(\mathrm{n}=27414)\end{array}$ & $\begin{array}{c}\text { Left the } \\
\text { workforce early } \\
(n=5169)\end{array}$ & $\begin{array}{l}\text { Entered the } \\
\text { workforce later } \\
(n=19094)\end{array}$ & $\begin{array}{l}\text { Discontinuous } \\
\text { work history } \\
(n=16378)\end{array}$ & $\begin{array}{l}\text { Never worked } \\
\text { outside home } \\
\quad(n=560)\end{array}$ & \\
\hline Age, mean (SD) & $61.9(7.3)$ & $65.3(7.5)$ & $63.3(7.1)$ & $64.2(7.1)$ & $65.9(7.4)$ & $63.1(7.3)$ \\
\hline \multicolumn{7}{|l|}{ Birth Cohort, n (\%) } \\
\hline 1910-19 & $1359(5.0)$ & $595(11.5)$ & $1232(6.5)$ & $1205(7.3)$ & $78(13.9)$ & $4469(6.5)$ \\
\hline $1920-29$ & $8704(31.7)$ & $2364(45.7)$ & $7187(37.6)$ & $7041(43.0)$ & $247(44.1)$ & $25543(37.2)$ \\
\hline 1930-39 & $12278(44.8)$ & $1687(32.7)$ & $8250(43.2)$ & $6400(39.1)$ & $192(34.3)$ & $28807(42.0)$ \\
\hline $1940-49$ & $5073(18.5)$ & $523(10.1)$ & $2425(12.7)$ & $1732(10.6)$ & $43(7.7)$ & $9796(14.3)$ \\
\hline \multicolumn{7}{|l|}{ Education, n (\%) } \\
\hline Less than High School & $957(3.5)$ & $359(7.0)$ & $1005(5.3)$ & $465(2.8)$ & $181(32.3)$ & $2967(4.3)$ \\
\hline High School or GED & $3876(14.1)$ & $1052(20.4)$ & $3139(16.4)$ & $2713(16.6)$ & $144(25.7)$ & $10924(15.9)$ \\
\hline Associates/Some College & $9148(33.4)$ & $1806(34.9)$ & $7654(40.1)$ & $6000(36.6)$ & $156(27.9)$ & $24764(36.1)$ \\
\hline College Degree & $2858(10.4)$ & $913(17.6)$ & $2019(10.6)$ & $2352(14.4)$ & $52(9.3)$ & $8194(12.0)$ \\
\hline More than College Degree & $10575(38.6)$ & $1039(20.1)$ & $5277(27.6)$ & $4848(29.6)$ & $27(4.8)$ & $21766(31.7)$ \\
\hline \multicolumn{7}{|l|}{ Birth history, n (\%) } \\
\hline None & $1361(5.0)$ & $123(2.4)$ & $425(2.2)$ & $293(1.8)$ & $8(1.4)$ & $2210(3.2)$ \\
\hline
\end{tabular}




\begin{tabular}{|c|c|c|c|c|c|c|}
\hline At Least One Birth & $21307(77.7)$ & $4666(90.3)$ & $17411(91.2)$ & $15293(93.4)$ & $533(95.2)$ & $59210(86.3)$ \\
\hline Missing & $4746(17.3)$ & $380(7.3)$ & $1258(6.6)$ & $792(4.8)$ & $19(3.4)$ & $7195(10.5)$ \\
\hline
\end{tabular}


Table 2. CVD cases, person-years, and age-adjusted CVD rates per 1000 person-years by paid and unpaid labor characteristics.

\begin{tabular}{|c|c|c|c|c|}
\hline Paid and unpaid labor characteristics & CVD cases & Person-years & CVD rate ${ }^{1}$ & $(95 \% \mathrm{CI})$ \\
\hline \multicolumn{5}{|l|}{ Paid labor history } \\
\hline Worked consistently through adult life & 2273 & 18081.11 & 82.9 & $(62.1,103.8)$ \\
\hline Left the workforce early & 508 & 3836.23 & 98.3 & $(51.1,145.5)$ \\
\hline Entered the workforce late & 1731 & 13119.35 & 90.7 & $(65.9,115.4)$ \\
\hline Discontinuous work history & 1592 & 12185.25 & 97.2 & $(70.6,123.8)$ \\
\hline Never worked outside home & 54 & 345.14 & 96.4 & $(0,213.8)$ \\
\hline \multicolumn{5}{|l|}{ Reproductive history } \\
\hline No birth & 171 & 1400.29 & 77.4 & $(35.8,151.2)$ \\
\hline At least one birth & 5368 & 41361.22 & 90.7 & $(76.6,104.7)$ \\
\hline Missing birth information & 619 & 4805.57 & 86.0 & $(45.5,126.6)$ \\
\hline
\end{tabular}

${ }^{1}$ Adjusted for age, $<55,55-59,60-64,65-69,50-74,>75$ 
Table 3. Associations of paid labor participation history with CVD risk by reproductive history.

\begin{tabular}{|c|c|c|c|c|c|c|}
\hline Reproductive history (n) & Paid labor participation history & $\mathbf{N}$ & $\mathrm{HR}^{1}$ & $(95 \% C I)$ & $\mathrm{HR}^{2}$ & $(95 \% \mathrm{CI})$ \\
\hline No Birth & Worked consistently through adult life & 1361 & 1.00 & & 1.00 & \\
\hline \multirow[t]{4}{*}{$(2210)$} & Left the workforce early & 123 & 0.90 & $(0.47,1.72)$ & 0.92 & $(0.48,1.77)$ \\
\hline & Entered the workforce late & 425 & 0.96 & $(0.65,1.43)$ & 0.96 & $(0.65,1.43)$ \\
\hline & Discontinuous work history & 293 & 0.84 & $(0.53,1.32)$ & 0.83 & $(0.53,1.31)$ \\
\hline & Never worked outside home & 8 & 1.40 & $(0.20,10.04)$ & 1.33 & $(0.18,9.60)$ \\
\hline \multirow[t]{5}{*}{ At Least One Birth } & Worked consistently through adult life & 21307 & 1.00 & & 1.00 & \\
\hline & Left the workforce early & 4666 & 0.89 & $(0.80,0.98)$ & 0.87 & $(0.78,0.96)$ \\
\hline & Entered the workforce late & 17411 & 0.97 & $(0.91,1.04)$ & 0.95 & $(0.88,1.01)$ \\
\hline & Discontinuous work history & 15293 & 0.91 & $(0.85,0.97)$ & 0.91 & $(0.85,0.97)$ \\
\hline & Never worked outside home & 533 & 0.95 & $(0.72,1.25)$ & 0.84 & $(0.63,1.11)$ \\
\hline \multirow[t]{5}{*}{ Birth Information Missing } & Worked consistently through adult life & 4746 & 1.00 & & 1.00 & \\
\hline & Left the workforce early & 380 & 1.12 & $(0.80,1.56)$ & 1.09 & $(0.78,1.52)$ \\
\hline & Entered the workforce late & 1258 & 1.14 & $(0.93,1.40)$ & 1.13 & $(0.92,1.39)$ \\
\hline & Discontinuous work history & 792 & 1.36 & $(1.08,1.70)$ & 1.34 & $(1.06,1.68)$ \\
\hline & Never worked outside home & 19 & 1.03 & $(0.26,4.14)$ & 0.97 & $(0.24,3.89)$ \\
\hline
\end{tabular}

${ }^{1}$ Adjusted for age and 10-year birth cohort (1910-19, 20-29, 30-39, and 40-49); ${ }^{2}$ Adjusted for age, birth cohort, and educational attainment

Table S1. Sensitivity Analysis - 4 groups of paid labor participation (combined entered workforce late and discontinuous). 
Associations of paid labor participation history with CVD risk by reproductive history.

\begin{tabular}{|c|c|c|c|c|c|c|}
\hline Reproductive history (n) & Paid labor participation history & $\mathbf{N}$ & $\mathbf{H R}^{1}$ & $(95 \% \mathrm{CI})$ & $\mathbf{H R}^{2}$ & $(95 \% C I)$ \\
\hline No birth & Worked consistently through adult life & 1361 & 1.00 & & 1.00 & \\
\hline \multirow[t]{3}{*}{$(2210)$} & Left the workforce early & 123 & 0.90 & $(0.47,1.72)$ & 0.92 & $(0.48,1.77)$ \\
\hline & Entered the workforce late/discontinuous & 718 & 0.90 & $(0.65,1.26)$ & 0.90 & $(0.65,1.26)$ \\
\hline & Never worked outside home & 8 & 1.40 & $(0.20,10.04)$ & 1.33 & $(0.18,9.60)$ \\
\hline At least one birth & Worked consistently through adult life & 21307 & 1.00 & 1.00 & 1.00 & \\
\hline \multirow[t]{3}{*}{$(59210)$} & Left the workforce early & 4666 & 0.89 & $(0.80,0.98)$ & 0.87 & $(0.78,0.97)$ \\
\hline & Entered the workforce late/discontinuous & 32704 & 0.94 & $(0.89,0.99)$ & 0.93 & $(0.88,0.98)$ \\
\hline & Never worked outside home & 533 & 0.95 & $(0.71,1.25)$ & 0.84 & $(0.63,1.11)$ \\
\hline Birth information missing & Worked consistently through adult life & 4746 & 1.00 & & 1.00 & \\
\hline \multirow[t]{3}{*}{$(7195)$} & Left the workforce early & 380 & 1.12 & $(0.80,1.56)$ & 1.09 & $(0.78,1.52)$ \\
\hline & Entered the workforce late/discontinuous & 2050 & 1.23 & $(1.04,1.45)$ & 1.21 & $(1.02,1.44)$ \\
\hline & Never worked outside home & 19 & 1.03 & $(0.26,4.14)$ & 0.97 & $(0.24,3.89)$ \\
\hline
\end{tabular}

${ }^{1}$ Adjusted for age and 10-year birth cohort (1910-19, 20-29, 30-39, and 40-49 [=ref]); ${ }^{2}$ Adjusted for age, birth cohort, and educational attainment (college or more is reference group) 
Table S2. Sensitivity analysis - 4 groups of paid labor participation (combined entered workforce late and worked consistently through adult life). Associations of paid labor participation history with CVD risk by reproductive history.

\begin{tabular}{|c|c|c|c|c|c|c|}
\hline Reproductive history (n) & Paid labor participation history & $\mathbf{N}$ & $\mathbf{H R}^{1}$ & $(95 \% C I)$ & $\mathbf{H R}^{2}$ & $(95 \% C I)$ \\
\hline No birth & Worked consistently / entered workforce late & 1786 & 1.00 & & 1.00 & \\
\hline \multirow[t]{3}{*}{$(2210)$} & Left the workforce early & 123 & 0.91 & $(0.48,1.73)$ & 0.93 & $(0.49,1.78)$ \\
\hline & Discontinuous & 293 & 0.84 & $(0.54,1.31)$ & 0.84 & $(0.54,1.31)$ \\
\hline & Never worked outside home & 8 & 1.41 & $(0.20,10.12)$ & 1.34 & $(0.19,9.68)$ \\
\hline \multirow{4}{*}{$\begin{array}{l}\text { At Least One Birth } \\
(59210)\end{array}$} & Worked consistently /entered workforce late & 38718 & 1.00 & 1.00 & 1.00 & \\
\hline & Left the workforce early & 4666 & 0.90 & $(0.82,0.99)$ & 0.89 & $(0.81,0.99)$ \\
\hline & Discontinuous & 15293 & 0.92 & $(0.87,0.98)$ & 0.93 & $(0.88,0.99)$ \\
\hline & Never worked outside home & 533 & 0.96 & $(0.73,1.27)$ & 0.86 & $(0.65,1.14)$ \\
\hline \multirow{4}{*}{$\begin{array}{l}\text { Birth Information Missing } \\
\text { (7195) }\end{array}$} & Worked consistently /entered workforce late & 6004 & 1.00 & & 1.00 & \\
\hline & Left the workforce early & 380 & 1.08 & $(0.78,1.51)$ & 1.06 & $(0.76,1.47)$ \\
\hline & Discontinuous & 792 & 1.32 & $(1.06,1.64)$ & 1.30 & $(1.04,1.62)$ \\
\hline & Never worked outside home & 19 & 1.0 & $(0.25,4.01)$ & 0.93 & $(0.23,3.76)$ \\
\hline
\end{tabular}

${ }^{1}$ Adjusted for age and 10-year birth cohort (1910-19, 20-29, 30-39, and 40-49 [=ref]); ${ }^{2}$ Adjusted for age, birth cohort, and educational attainment (college or more is reference group). 
Table S3. CVD cases, person-years, and age-adjusted CVD rates by unpaid labor characteristic (assuming missing live birth information of never married women meant no live births).

\begin{tabular}{lllll}
\hline Unpaid Labor Characteristic & CVD cases & Person-years & CVD rate $^{\mathbf{1}}$ & $\mathbf{( 9 5 \% ~ C I ) ~}^{\text {Reproductive history }}$ \\
No birth & 393 & 3100.93 & 81.9 & $(32.0,131.7)$ \\
At Least One Birth & 5368 & 41361.22 & 90.7 & $(76.6,104.7)$ \\
Birth Information Missing & 397 & 3104.94 & 86.2 & $(35.5,136.8)$ \\
\hline
\end{tabular}

${ }^{1}$ Adjusted for age, $<55,55-59,60-64,65-69,50-74,>75$, per 1000 person-years 
Table S4. Associations of paid labor participation history with CVD risk by reproductive history (assuming missing live birth info of never married women meant no live births).

\begin{tabular}{|c|c|c|c|c|c|c|}
\hline $\begin{array}{l}\text { Reproductive } \\
\text { history (n) }\end{array}$ & $\begin{array}{l}\text { Paid labor participation } \\
\text { history }\end{array}$ & $\mathbf{N}$ & $\mathbf{H R}^{1}$ & $(95 \% \mathrm{CI})$ & $\mathbf{H R}^{2}$ & $(95 \% \mathrm{CI})$ \\
\hline \multirow[t]{5}{*}{$\begin{array}{l}\text { No birth } \\
\text { (4798) }\end{array}$} & $\begin{array}{l}\text { Worked consistently through } \\
\text { adult life }\end{array}$ & 3356 & 1.00 & & 1.00 & \\
\hline & Left the workforce early & 166 & 1.08 & $\begin{array}{l}(0.64, \\
1.82)\end{array}$ & 1.10 & $\begin{array}{l}(0.65 \\
1.85)\end{array}$ \\
\hline & Entered the workforce late & 850 & 0.95 & $\begin{array}{l}(0.73, \\
1.24)\end{array}$ & 0.96 & $\begin{array}{l}(0.73 \\
1.24)\end{array}$ \\
\hline & Discontinuous work history & 413 & 0.84 & $\begin{array}{l}(0.58, \\
1.22)\end{array}$ & 0.84 & $\begin{array}{l}(0.58 \\
1.22)\end{array}$ \\
\hline & Never worked outside home & 13 & 0.76 & $\begin{array}{l}(0.10 \\
5.41)\end{array}$ & 0.73 & $\begin{array}{l}(0.10 \\
5.19)\end{array}$ \\
\hline At Least One Birth & $\begin{array}{l}\text { Worked consistently through } \\
\text { adult life }\end{array}$ & 21307 & 1.00 & & 1.00 & \\
\hline \multirow[t]{4}{*}{$(59210)$} & Left the workforce early & 4666 & 0.89 & $\begin{array}{l}(0.80, \\
0.98)\end{array}$ & 0.87 & $\begin{array}{l}(0.79, \\
0.97)\end{array}$ \\
\hline & Entered the workforce late & 17411 & 0.97 & $\begin{array}{l}(0.91 \\
1.04)\end{array}$ & 0.95 & $\begin{array}{l}(0.88 \\
1.01)\end{array}$ \\
\hline & Discontinuous work history & 15293 & 0.91 & $\begin{array}{l}(0.85 \\
0.97)\end{array}$ & 0.91 & $\begin{array}{l}(0.85 \\
0.97)\end{array}$ \\
\hline & Never worked outside home & 533 & 0.95 & $\begin{array}{l}(0.72, \\
1.25)\end{array}$ & 0.84 & $\begin{array}{l}(0.63 \\
1.11)\end{array}$ \\
\hline \multirow{3}{*}{$\begin{array}{l}\text { Birth Information } \\
\text { Missing } \\
(4607)\end{array}$} & $\begin{array}{l}\text { Worked consistently through } \\
\text { adult life }\end{array}$ & 2751 & 1.00 & & 1.00 & \\
\hline & Left the workforce early & 337 & 1.12 & $\begin{array}{l}(0.77, \\
1.62)\end{array}$ & 1.09 & $\begin{array}{l}(0.75 \\
1.58)\end{array}$ \\
\hline & Entered the workforce later & 833 & 1.28 & $\begin{array}{l}(0.99 \\
1.66)\end{array}$ & 1.25 & $\begin{array}{l}(0.97 \\
1.62)\end{array}$ \\
\hline
\end{tabular}




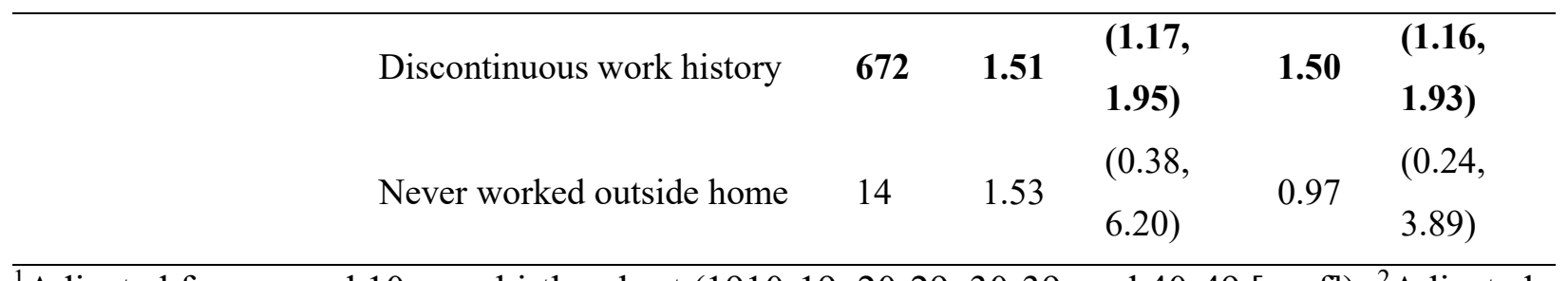

${ }^{1}$ Adjusted for age and 10-year birth cohort (1910-19, 20-29, 30-39, and 40-49 [=ref]); ${ }^{2}$ Adjusted for age, birth cohort, and educational attainment 